\title{
ENERGIA E SUSTENTABILIDADE EM AGROECOSSISTEMAS
}

\author{
ENERGY AND SUSTAINABILITY IN AGROECOSYSTEMS
}

\section{Gilberto Vilmar Kozioski ${ }^{1}$ Maria de Lourdes Santorio Ciocca ${ }^{2}$}

\section{- REVISÃO BIBLIOGRÁFICA -}

RESUMO

Os sistemas de produção de alimentos atualmente predominantes no país e no mundo têm sido frequentemente questionados em função de vários faiares, destacando-se entre eles, aqueles associados ao uso da energia. O objetivo desta revisão é apresentar alguns dados sobre a origem e eficiência da utilização de energia na produção animal e vegetal, assim como sobre a distribuição do seu uso no mundo, relacionando estes aspectos com a sustentabilidade dos sistemas alimentares predominantes no mundo e no Brasil. A principal fonte de energia atualmente utilizada, mundialmente, no processo produtivo e na cadeia alimentar total é derivada do petróleo, cujas reservas mundiais são limitadas e com estimativas de esgotamento até meados do próximo século. Além disso, a utilização da maior parte da energia e. conseqüentemente, a produção e consumo da maior parle dos alimentos no mundo é feita por uma minoria da população existente em algumas poucas regiões do Hemisfério Norte. Finalmente, os sistemas intensivos de produção animal e vegetal são mais produtivos mas, de outra parte, são energeticamente mais ineficientes que sistemas menos intensivos. No Brasil, a maior parte da produção agropecuária deriva de sistemas intensivos de produção e, além disso, os cultivos são, predomi nantemente, de natureza comercial elou industrial, em detrimento dos cultivos alimentares. Dessa maneira, por um lado, face à grande dependência por insumos externos, energeticamente onerosos e esgotáveis e, por outro, face à dependência e insegu-ridade alimentar do país, pode-se considerar que os agroecossistemas brasileiros são frágeis $e$

\begin{abstract}
insustentáveis, necessitando serem reavaliados num curto prazo, tanto em relação às políticas públicas para o setor como também em relação ao direcionamento da pesquisa.
\end{abstract}

Palavras-chave: agroecossistemas, energia, sustentabilidade.

SUMMARY

Food production systems presenfly practiced in Brazil anã $m$ lhe worid are being subjected to questioning due to several factors, such as those associated to energy use. The objective of this review is to show some data about source and efficiency of energy use in animal and plant production and, moreover, about distribution ofits use in lhe wortd, relating this aspects to lhe sustainability of predominam food systems in the wortd and in Brazil. The main energy source presentty used in the productive process and in the ove rall food chain is derivedfrom petroleum, which worid reserves are limüed and estimated to exhaust around the middie ofthe next century. Moreover, the use of most part of the energy, and consequentiy most offood in the worid is produced and consumed by a small population in afew regions of the Northem Hemisphere. Finally, intensive production systems of animais and plants are more productive, but, on the other hand, are less efficient in te mis of energy use as comparta to less intensive systems. In Brazil, the greater part of plant and animal production come from intensive production systems and, moreover, plant systems are predominanfly of commercial and/or industrial character, $m$ detrimental of alimentary systems. Thus, due to the great dependence of externai inputs, which are energy-

\footnotetext{
${ }^{1}$ Aluno do Curso de Pós-Graduação em Zootecnia, Universidade federal do Rio Grande do Sul (UFRGS), Av.: Bento Gonçalves, 7712, 91540-000, Porto Alegre - RS. E-mail: kozloski@ mousenet.com.br. Autor para correspondência.

${ }^{2}$ Professor Adjunto, Departamento de Zootecnia, UFRGS
} 
expensive and exhaustíble. and to the food dependence and insecurity in Brcail, it is possible to consider Brazilian agroecosystems as fragile and unsustainable, needing a short temi revaluation as to public policies for this sector as well as to research objectives.

Key words: agroecosystems, energy, sustainability

\section{INTRODUÇÃO}

\begin{abstract}
Após a segunda grande guerra, a agricultura mundial sofreu profundas transformações, que foram caracterizadas pela intensificação, especialização, padronização e internacionalização dos produtos e do processo produtivo, e que constituíram a base da chamada Revolução Verde. A Revolução Verde foi baseada no paradigma tecnológico fundamentado pela modificação das condições naturais para favorecer o potencial genético de plantas e animais (FAO, 1995a).
\end{abstract}

O desenvolvimento da agricultura durante a Revolução Verde foi desigual nas diferentes regiões do mundo, favorecendo o aumento da concentração da renda e da produção de alimentos nos países desenvolvidos e um aumento da pobreza e da dependência por alimentos nos subdesenvolvidos (B RUM, 1988). Além disso, os sistemas intensivos de produção agrícola têm causado sérios danos ambientais caracterizados, por um lado, pelo rápido esgotamento de recursos naturais e, por outro, pela poluição e/ou contaminação devido à excessiva liberação de componentes residuais no meio ambiente.

Desse modo, em virtude de crescentes críticas que vem recebendo, abordagens alternativas têm surgido e se difundido ao longo dos últimos anos, as quais parecem convergir na avaliação de que o atual modelo agrícola é insustentável, e de que os parâmetros a serem avaliados para considerar algum aceitável deve ser mais amplo que aqueles monetários, devendo incluir o custo e/ou impacto ambiental ou, até mesmo, o impacto sócioeconômico e cultural.

A Comissão Mundial para o Meio Ambiente e Desenvolvimento, ligada à FAO (Organização das Nações Unidas para a Agricultura e Alimentação), conceitua desenvolvimento sustentável como sendo um "processo dinâmico destinado a satisfazer as necessidades atuais sem comprometer a capacidade das gerações futuras de atenderem suas próprias necessidades". Agricultura sustentável, especificamente, é considerado aqui como sendo a "habilidade de um sistema agrícola em manter a produção através do tempo, face distúrbios ecológicos e pressões socio-econômicas de longo prazo" (ALTIERE, 1987 apud ALMEIDA, 1997). Desse modo, a sua sustentabilidade não depende somente de um, mas sim, de um conjunto de fatores ecológicos e sócio-econômicos aluando interativamente, entre os quais aqueles associados ao uso da energia.

Sob esse ponto de vista, é de interesse a análise da origem e da eficiência do uso da energia nos sistemas de produção animal e vegetal e, sob uma perspectiva mais ampla, da distribuição do uso da energia nas diferentes regiões do mundo. O objetivo desta revisão é fazer essa análise e relacioná-la com a sustentabilidade dos sistemas de produção agrícola predominantes no mundo e no Brasil.

\section{AGROECOSSISTEMAS}

Em biologia, um conjunto de organismos vivos associados ao seu ambiente físico e químico é denominado ecossistema (HEITSCHMIDT et al., 1996). Agroecossistemas são ecossistemas agrícolas que têm como objetivo básico a manipulação dos recursos naturais com vistas a otimizar a captura da energia solar e transferi-la para as pessoas na forma de alimentos ou fibras. Além disso, nos agroecossistemas, o homem é um componente ativo, que organiza e gestiona os recursos do sistema (HECHT, 1991). Desse modo, é apropriado salientar que é incorporado ao objetivo inicial básico, aqueles de natureza sócio-econômicos, como por exemplo, a obtenção do lucro, na agricultura empresarial capitalista, ou, na agricultura familiar, a sobrevivência e estabilidade da unidade familiar de produção. Um outro aspecto importante é que a definição dos limites de um agroecossistema vai depender da amplitude do objeto de estudo. Nesse caso, um agroecossistema pode ser considerado uma cultura ou uma criação dentro de uma unidade de produção, pode ser a unidade de produção em si, pode ser o conjunto das unidades de produção de uma região, de um país, ou mesmo, do mundo todo. Num agroecossistema, podem estar envolvidos também os elementos e/ou fatores externos às unidades de produção, que de uma forma ou de outra influenciam e/ou determinam a sua dinâmica, como os setores de apoio técnico ou creditício, o mercado, as indústrias de insumos e de transformação, entre outros (ALTIERI \& YURJEVIC, 1991).

\section{FONTE DE ENERGIA}

As fontes de energia utilizadas nos agroecossistemas podem ser limitantes a sua sustentabilidade devido a pelo menos dois aspectos: se são renováveis ou não, e se são poluidoras do meio ambiente ou não. 
Nas últimas décadas, a principal fonte energética utilizada em, praticamente, todos os setores tem sido o petróleo, o qual supre atualmente em tomo de $80 \%$ da demanda mundial de energia (FAO, 1980; OLIVEIRA, 1987). Embora no Brasil a energia hidráulica vem tendo uma participação mais importante e, recentemente, até mesmo predominante no uso geral (IBGE, 1996), o uso de energia nos agroecossistemas mais intensivos do país provavelmente seja ainda, predominantemente, de origem fóssil. Em um estudo realizado no início da década de 80 , verificou-se que $79,6 \%$ da energia gasta nos sistemas agropecuários do Estado de São Paulo, representativo dos sistemas agrícolas intensivos do país, era de origem fóssil (REDE TECNOLOGIAS ALTERNATIVAS/SUL, 1997).

A dependência dos agroecossistemas por combustíveis de origem fóssil toma-os insustentáveis à medida que essa fonte de energia não é renovável e suas reservas são limitadas. Segundo dados e estimativas da FAO (1980), a taxa de consumo de petróleo atingirá um nível máximo no final do século $\mathrm{XX}$ e terá as suas reservas esgotadas em meados do século XXI. Outras estimativas, no entanto, são mais pessimistas e pressupõem o esgotamento das reservas de petróleo em menos de 40 anos, seguindo as atuais taxas de crescimento anual do consumo de energia, de $0,7 \%$ na Europa, 1,3\% na América do Norte e 3,6\% nos países subdesenvolvidos (AMIGOS DE LA TIERRA-PAÍSES BAJOS, 1994).

$\mathrm{O}$ outro aspecto a ser considerado em relação à fonte de energia é o impacto ambiental decorrente do seu uso. O uso de combustíveis fósseis tem sido considerado a principal causa do chamado "efeito estufa" na Terra, ou seja, de um aumento exagerado da temperatura na atmosfera terrestre(SPEDDING, 1995). O aumento da temperatura é decorrente da capacidade que têm alguns gases, como o dióxido de carbono e o metano, de absorver energia de ondas na faixa do infravermelho do espectro eletromagnético. Estimase que as emissões de dióxido de carbono na atmosfera, decorrentes da queima de combustíveis fósseis, está ao redor de 20 bilhões de ton/ano (AMIGOS DE LA TIERRAPAÍSES BAJOS, 1994). No ciclo natural do carbono, cerca de 85 bilhões de toneladas de $\mathrm{CO}_{2}$ são produzidos anualmente pela degradação microbiana da celulose, o principal produto originado da fotossíntese (VAN SOEST, 1982). Desse modo, a adição desse gás no ambiente, derivado da queima dos combustíveis fósseis, é bastante significativa e suficiente para determinar um aumento da temperatura média na atmosfera de $0,3 \%$ a cada dez anos, taxa duas vezes mais alta que aquela considerada normal, que, segundo publicação da organização não governamental AMIGOS DE LA TIERRA-PAÍSES BAJOS (1994), é de $0,1 \% /$ década. Em função disso, esta organização estima, com base na quantidade consumida em 1985, que o consumo de energia de origem fóssil no mundo deve reduzir em média 50\% (85\% nos países industrializados) até o ano 2030 para que não aconteça um colapso ambiental e, entre as medidas técnicas sugeridas para tanto, está a redução no uso de fertilizantes químicos.

COOK (1971) apresentou que, do consumo per capita total de energia na sociedade norte-americana nos anos 70, aproximadamente $45 \%$ estava associado a alimentação, indústria e agricultura, $27 \%$ ao transporte e $28 \%$ ao gasto comercial e residencial. No entanto, este estudo não permite identificar claramente qual a participação do sistema alimentar como um todo, ou seja, desde a produção até o consumo final dos alimentos, no gasto total de energia pelas sociedades modernas. Mas é provável que, de forma direta ou indireta, tenha uma participação predominante e, sendo assim, constitui-se no setor que pode ser afetado mais profundamente por mudanças no padrão energético.

\section{EFICIÊNCIA DO USO DA ENERGIA NOS AGROECOSSISTEMAS}

O estudo da eficiência do uso da energia para avaliação da sustentabilidade de agroecossistemas tem recebido atenção especial nos anos recentes. No entanto, já no século passado, havia estudos de economias como sistemas de conversão de energia e, no início dos anos 70, estudos de balanço energético em culturas como a do milho eram desenvolvidos na Universidade de Cornell, nos EUA (ALIER, 1996).

Usualmente, a eficiência é medida pelo balanço de energia ou pela relação output/input, a qual é conduzida determinando-se a quantidade de energia obtida na forma de produto em relação à energia cultural utilizada no sistema para produzi-lo (HEITSCHMIDT et al., 1996). Energia cultural é toda a forma de energia manipulada diretamente pelo homem para o seu uso, como a energia do petróleo, hidráulica, eólica, nuclear, ou outras. O output de energia é determinado pela conversão direta do rendimento de produtos ( $\mathrm{kg}$ de grãos, carne, leite, lã, outros) em energia (kcal ou kj), de acordo com o conteúdo de energia bruta de cada unidade de produto. $\mathrm{O}$ input de energia é de natureza mais complexa, podendo incluir amplos e variáveis tipos de entrada de energia, como a energia gasta pelo trabalho humano, pelo transporte de insumos e produtos, energia gasta na manufatura das máquinas, 
implementos e insumos agrícolas, energia gasta na armazenagem e industrialização dos produtos, entre outros, cuja identificação e quantificação exata são mais difíceis de serem feitas. A energia solar não é considerada nesta avaliação por se tratar de uma fonte de energia "renovável" do ponto de vista conceituai, e por não ser, a princípio, um elemento limitante da sustentabilidade dos sistemas agropecuários. De qualquer maneira, a relação output/input tem valor à medida que nos dá uma indicação do nível de dependência de um agroecossistema qualquer por fontes externas de energia e da possibilidade de sobrevivência daquele modelo diante da fínitude de tais fontes de energia (HEITSCHMIDT et al., 1996).

BOWMAN (1980) apresentou e discutiu alguns dados da relação entre o input e o output de energia em diferentes sistemas de produção vegetal, e observou que naqueles associados à produção de subsistência, o balanço de energia cultural tende a ter valores positivos mais altos que nas de padrão mais intensivo e de caráter comercial (em tomo de 14 vs 1,5). Isso também é demonstrado pela comparação de diferentes sistemas de produção de arroz e de milho, onde os sistemas com maior input têm um maior rendimento de grãos por área, mas têm um balanço energético com valores positivos mais baixos que os sistemas com menor input (FAO, 1980; HEITSCHMIDT et al., 1996). No caso específico da produção de milho dos Estados Unidos, a tecnologia introduzida com a Revolução Verde permitiu, por um lado, um aumento na produtividade de 2,4 vezes de 1945 a 1970 mas, por outro, o gasto de combustíveis fósseis aumentou 3,1 vezes neste período. Isso determinou uma diminuição na eficiência energética, sendo que a relação output/input de energia reduziu de 3,7 em 1945 para 2,82 em 1970 (PIMENTEL et al., 1973).

Das várias atividades presentes nos agroecossistemas e que consomem energia cultural, destacam-se a irrigação, a manufatura dos fertilizantes químicos, o uso de combustíveis e a fabricação da maquinaria agrícola. Em sistemas intensivos de produção de arroz irrigado, esses itens chegam a representar, respectivamente, $42,17,15 \mathrm{e}$ $6 \%$ e em sistemas de produção de milho (não irrigado). O, 37, 28 e 14\% da energia cultural total gasta no sistema (PIMENTEL $\boldsymbol{e t}$ al., 1973; FAO, 1980). Os fertilizantes químicos, nas duas situações apresentadas, têm uma participação importante. Dentre eles, os adubos nitrogenados destacam-se por geralmente serem adicionados em maiores quantidades, quando comparados aos potássicos e fosfatados, e por consumirem maior quantidade de energia na forma de petróleo para sua manufatura $(2,00 ; 0,33$ e $0,21 \mathrm{~kg}$ de combustível fóssil $/ \mathrm{kg}$ de fertilizante nitrogenado, fosfatado e potássico, respectivamente (FAO, 1980)). No Brasil, o consumo de fertilizantes químicos (NPK) aumentou significativamente a partir do final da década de sessenta, alcançando, em 1995, o consumo de aproximadamente 11 milhões de toneladas (IBGE, 1996). Certamente isso representa um importante item do consumo de energia nos agroecossistemas do país, equivalendo a, aproximadamente, 9 milhões de toneladas de combustível fóssil.

STEINHART \& STEINHART (1974), de outra forma, analisaram a eficiência energética de diferentes agroecossistemas considerando, além da energia gasta na produção em si, também a energia gasta no processamento, comercialização, conservação e preparação dos alimentos. Nessas condições, verificaram que as culturas de subsistência eram as mais eficientes (com uma relação output/input variando em tomo de 10 a 33), enquanto que a produção intensiva de grãos e de bovinos em campos naturais, embora com balanço positivo, eram menos eficientes (relação output/input em tomo de 2 a 5). Já os sistemas de produção de leite à base de pastagem cultivada apresentaram uma relação output/input de energia equilibrada, enquanto os de produção intensiva de ovos e de bovinos de corte em pastagem cultivada tiveram uma relação negativa (relação output/input em tomo de 0,2 a 0,3). Por sua vez, os sistemas confinados de bovinos de corte, destacaram-se como sendo os mais ineficientes (relação output/input menor que 0,1 ).

Utilizando os mesmos critérios que constituíram o estudo acima referido, os mesmos autores fizeram também uma avaliação do sistema alimentar como um todo, vigente nos Estados Unidos na década de 70 e que é considerado um padrão da Revolução Verde. Verificaram que, de 1945 a 1970, o input de energia para obter uma caloria na forma de alimento humano foi crescente, e que, em 1970, aquela gasta na produção em si, representava somente em tomo de um quarto do total de energia gasto no sistema todo.

O estudo da eficiência de sistemas de produção animal, por sua vez, toma-se cada vez mais pertinente, à medida que os rebanhos mundiais das principais espécies de animais domésticos são significativos e crescentes (em tomo de 3,0;1,0 e 13,0 bilhões de ruminantes, suínos e aves, respectivamente (FAO, 1995b)). No Brasil, no ano de 1990, cerca de 15 milhões de toneladas de grãos ( $\pm 25 \%$ da produção total de grãos) foram utilizadas na alimentação animal (DENARDI, 1990) e estimase que, em tomo de 1/6 da energia consumida pelas criações animais no mundo, provém dos grãos (OLTJEN \& BECKETT, 1996). Embora a maior 
parte desses grãos seja consumida por aves e suínos $(59 \%)$ e a menor pêlos ruminantes (37\%), a produção de energia pelas criações, na forma de alimentos para o homem, no entanto, tem sido, em sua maior parte, derivada dos ruminantes (61 vs $39 \%)$.

Os sistemas de produção animal têm um balanço energético com valores quase sempre negativos, destacando-se os de produção avícola como os mais ineficientes, com uma relação output/input em tomo de 0,1 (BOWMAN, 1980). Adicionalmente, WATHES (1981) comparou diferentes sistemas de produção de ovos da Inglaterra, em gaiolas, semiconfinados e livres, verificando que todos eles eram igualmente ineficientes em relação ao uso de combustíveis fósseis (apresentando em média uma relação output/input de energia de 0,15$)$. Os sistemas de criação livres tinham menor gasto de energia cultural associado à infra-estrutura, mas as aves consumiam maior quantidade de ração para compensar o gasto de energia com atividade e regulação da temperatura corporal.

HEITSCHMIDT et al. (1996), por sua vez, avaliaram diferentes sistemas de produção de bovinos de corte prevalentes nos EUA, nos quais eram usados alimentos concentrados e conservados em diferentes. fases da criação. Observaram que todos eles têm um balanço de energia consideravelmente negativo, apresentando valores da relação output/input de 0,18 a 0,40. Esses resultados podem ser explicados pelo fato de que grãos e forragens conservadas constituem insumos

Tabela 1 - Relação entre o gasto de energia cultural e produção de algumas matérias primas utilizadas na alimentação animal*

MATÉRIA PRIMA

Kcal gasto/kg de MS

TAMMINGA, 1996 HEITSCHMIDT et al., 1996

\begin{tabular}{lcc}
\hline Campo natural & - & 0 \\
Pastagem cultivada & $382-741$ & 280 \\
Feno de alfafa & 358 & 350 \\
Silagem de milho & 645 & 617 \\
Cevada (grãos) & 2151 & 855 \\
Milho (grão) & 2151 & - \\
Farelo de soja & 1625 & - \\
Ração de engorda (bovinos) & - & 1023 \\
Concentrado protéico (bovinos) & - & 1546
\end{tabular}

* Os valores da tabela representam o gasto de energia associada com a operação, manufatura, distribuição, manutenção e depreciação de equipamentos e produtos utilizados na produção das matérias primas, sendo que os valores diferentes para um mesmo produto podem estar refletindo diferenças de metodologia na estimativa do gasto energético ou diferenças associadas às condições de produção da matéria prima. na produção animal que tem custo energético de produção mais alto que pastagens cultivadas e, principalmente, que nativas, como pode ser observado na tabela 1. Também, dentre as espécies de animais domésticos, os bovinos de corte estão entre os menos eficientes quanto à transformação da energia do alimento no produto carne (FARIA \& CORSI, 1988; CHURCH, 1980). Somente em tomo de $4 \%$ da energia consumida por essa espécie é convertida em carcaça para o consumo humano, que é uma eficiência em tomo de quatro vezes menor que a apresentada por suínos e seis vezes menor que a de bovinos de leite e de aves.

Outro aspecto a ser considerado na avaliação do uso da energia em sistemas de produção animal é a eficiência com que eles transformam a energia da ração, potencialmente utilizável pelo homem, em energia na forma de produto final, ou seja, o nível de competição pelo alimento entre uma criação animal e o homem. Essa relação é quantificada através do índice de retorno humano, que representa a proporção da energia das matérias primas comumente fornecidas aos animais que é transformada em produto animal utilizável pelo homem, comparada com a energia que ele utilizaria se consumisse a matéria prima diretamente. Entre as espécies domésticas, os bovinos de leite são os que têm a mais alta e as aves de corte a mais baixa eficiência potencial de transformação de seu alimento em produto humano (CHURCH, 1980). No entanto, nos ruminantes essa eficiência varia com o tipo de alimento utilizado no sistema. OLTJEN \& BECKETT (1996) estudaram alguns sistemas de produção de bovinos existentes nos EUA e observaram que, nos de produção de leite, o retomo humano de energia na forma de leite era positivo $(128 \%)$ quando os animais recebiam subprodutos industriais em sua dieta e, negativo (57\%), quando as dietas eram a base de grãos de cereais. Nos de bovino de corte, que usavam altas quantidades de grãos nas dietas, o retomo era sempre negativo (28 a $37 \%$ ).

Com base nos dados da tabela 1 e nos estudos apresentados acima e, considerando-se somente a eficiência energética como critério para avaliar a sustentabilidade dos agroecossistemas, parece evidente que o sistema de produção animal mais eficiente é o de produção de ruminantes sobre campos naturais, cujo input de energia cultural é praticamente nulo (Tabela 1). Analisando da mesma forma, torna-se evidente também que, em 
geral, a produção intensiva de suínos e aves é energeticamente ineficiente, caracterizados por um balanço energético do sistema negativo e, inevitavelmente, com um retorno humano também negativo, por concorrerem diretamente com o homem pelo alimento (grãos). No entanto, se, por um lado, nos sistemas tradicionais de produção de bovinos sobre campos naturais, o balanço de energia cultural é significativamente positivo, por outro, tem sido demonstrado que eles têm degradado a biodiversidade e o solo dessas áreas (GONÇALVES et al., 1990, VAVRA, 1997) e apresentam uma produtividade muito baixa. No Rio Grande do Sul, a produtividade da pecuária de corte sobre campos naturais situa-se entre $25-85 \mathrm{Kg}$ de peso vivo/ha/ano (MARASCHIN, 1981, ZIMMER \& EUCLIDES FILHO, 1997), o que não permite o suprimento nem da demanda atual e muito menos, da demanda potencial futura por carne (JACQUES, 1990). De qualquer maneira, considerando os resultados da pesquisa de balanço energético apresentados anteriormente, seria mais racional e mais aceitável energeticamente que a base alimentar da produção de bovinos fosse alterada de uma com grãos para outra com pastagem e/ou subprodutos industriais. No caso da produção de aves e suínos, assim como para os ruminantes, do ponto de vista agroecológico, a aceitabilidade desses sistemas dependem, também, de outros fatores além da eficiência energética. $\mathrm{O}$ mercado pode ser considerado um dos elementos dos agroecossistemas e, dessa forma, também é um determinante de sua sustentabilidade. Embora ele seja conjuntural e diverso, se considerarmos que todos os indivíduos das sociedades tivessem real acesso aos alimentos e que a capacidade de produção de alimentos numa base agroecologicamente aceitável não tivesse sido esgotada, as sociedades poderiam optar, em determinado momento, entre consumir uma maior quantidade de energia e outros nutrientes diretamente na forma de grãos, ou uma menor quantidade destes, mas na forma de produto animal, como carne, ovos e seus subprodutos.

\section{DISTRIBUIÇÃO DO USO DA ENERGIA}

A distribuição do uso da energia também é um importante fator a ser considerado na avaliação da sustentabilidade dos agroecossistemas, porque ela está associada ao fluxo de matéria e de renda dentro e entre os sistemas. Isso implica que o fortalecimento relativo de um sistema produtivo resulta na fragilidade de outros, em função das relações de troca e/ou transferência que se estabelecem entre eles. Dados totais ou médias de produção e consumo de alimentos e, no caso, de consumo de energia, não refletem as reais condições dos sistemas produtivos ou os contrastes existentes entre as diferentes regiões do mundo e/ou numa mesma região. Esses contrastes são responsáveis, em grande parte, pela quebra da homeostase ambiental, pela geração de tensão social e, consequientemente, pela instabilidade dos agroecossistemas em várias regiões do mundo.

Sem dúvida, grande parte da crise social e ambiental estabelecida no mundo, atualmente, é consequência do fato que $25 \%$ da população mundial presente nos países industrializados consomem $75 \%$ dos recursos naturais e/ou produzidos na Terra (AMIGOS DE LA TIERRAPAÍSES BAJOS, 1994).

Embora tenham somente $16,7 \%$ da população, os países da Europa Ocidental e da América do Norte consomem $50 \%$ da energia, produzem $33,1 \%$ dos cereais, $40,7 \%$ da carne e $46,5 \%$ do leite do mundo (FAO, 1980, FAO, 1995b). Menos de $10 \%$ da população ativa desses países é ligada à atividade agrícola, enquanto que, nos subdesenvolvidos, quase $50 \%$ está envolvida nessa atividade (FAO, 1995b). Definitivamente, a maior parte dos alimentos do mundo são produzidos nos países industrializados em sistemas que exigem um alto input de insumos e/ou energia cultural. Embora os agroecossistemas sejam significativamente mais produtivos, consomem muito mais energia por área cultivada (doze vezes) e por trabalhador (cinquenta vezes) do que nos países subdesenvolvidos (FAO, 1980).

No Brasil, assim como em vários outros países subdesenvolvidos, o padrão de desenvolvimento do setor primário idealizado pela Revolução Verde foi adotado mais tarde que nos países do Primeiro Mundo, ou seja, em meados da década de 60. Entre os indicadores dessa mudança estão a transferência de um grande contingente da população ativa do setor primário para os setores secundário e terciário ou, de outra forma, de população do setor rural para o urbano a partir, principalmente, da década de 60 (IBGE, 1996).

O processo de "modernização" ou de intensificação da produção agropecuária no Brasil não se deu de maneira uniforme nas diferentes regiões e nem tampouco abrangeu as várias culturas e criações. A partir do final da década de 60, houve uma significativa expansão da área cultivada e um aumento na produtividade de cultivos como o milho, a soja e a cana de açúcar, e uma estagnação ou mesmo redução da área e da produtividade de cultivos, como o trigo e o feijão. Logicamente, a dinâmica evolutiva dessas diferentes culturas está diretamente associada à evolução do input de energia em cada uma delas. $\mathrm{O}$ aumento da 
produtividade dos primeiros deve-se, em grande parte, além da utilização de cultivares mais produtivas, à utilização maciça de fertilizantes químicos e agrotóxicos. De 1964 a 1979, o consumo de agrotóxicos aumentou 421\% (REDE TECNOLOGIAS ALTERNATIVAS/SUL, 1997) e em 1995, somente as três principais culturas, ou seja, o milho, a cana-de-açúcar e a soja foram os responsáveis por, aproximadamente, $60 \%$ do consumo total de fertilizantes químicos no país (IBGE, 1996).

$\mathrm{Na}$ produção animal, o processo de intensificação foi bastante significativo na avicultura e suinocultura e, raticamente, não existiu no setor de bovinos. Conforme dados do IBGE (1970, 1980, 1996), principalmente a partir dos anos 70 , houve uma grande expansão do rebanho avícola, contrastando com uma menor evolução dos rebanhos bovinos e suínos. Nesse período, o desfrute no setor avícola triplicou (115 vs 305\%) e o de suínos duplicou (24 vs $41 \%$ ), enquanto que o de bovinos de corte não evoluiu (em tomo de 11\%). Da mesma forma como para os cultivos, a dinâmica evolutiva dos diferentes setores da produção animal também está diretamente associada à evolução do input de energia em cada setor. O incremento do desfrute nos setores avícola e suinícola indica a utilização de um novo padrão tecnológico, como animais "melhorados" geneticamente, uso mais intensivo de medicamentos, aditivos biológicos e outros princípios ativos químicos, rações balanceadas, ambiente controlado, entre outros.

\section{CONSIDERAÇÕES FINAIS}

Atualmente, a disponibilidade per capita mundial e anual de alimentos é de aproximadamente $270 \mathrm{~kg}$ de cereais (já descontado a parte consumida pelas criações de $1 / 6$ do total), $36 \mathrm{~kg}$ de carne e $93 \mathrm{~kg}$ de leite (FAO, 1995b). Essa quantidade de alimentos seria suficiente para suprir a demanda calórica da população mundial se fosse uniformemente distribuída. No entanto, como visto anteriormente, a maior parte dessa produção é realizada e consumida por uma minoria da população mundial presente nos países industrializados, a partir de sistemas produtivos ambientalmente degradantes, energeticamente ineficientes, e dependentes de altos impus de insumos industriais e de uma fonte de energia não renovável (combustível fóssil).
Em relação ao uso da energia nos agroecossistemas, especificamente, a discussão de alternativas tem por base o paradoxo estabelecido de que, quanto menor o input de energia cultural no sistema, maior será a sua eficiência, mas menor será sua produtividade. $\mathrm{O}$ impacto que esse paradoxo está produzindo ou virá a produzir na produção de alimentos, provavelmente, será diferente nas diferentes regiões do mundo. $\mathrm{Na}$ figura 1 , é apresentada a evolução relativa da produção per capita de alimentos em algumas regiões do mundo ao longo de dez anos a partir de meados da década de 80. Observa-se nesta figura que, na Europa, a produção de alimentos vem reduzindo ao longo dos últimos anos, provavelmente em consequência de sua reestruturação económica em curso e diminuição dos subsídios agrícolas, de problemas ambientais decorrentes do modelo agrícola intensivo adotado no Pós-Guerra e, principalmente, da existência de grandes quantidades de excedentes de alimentos. A produção de alimentos na América do Norte teve um comportamento de queda e de aumento ao longo do período analisado, provavelmente condicionado mais pelo mercado internacional dos produtos agrícolas do que por questões ecológicas, já que parte significativa da produção agrícola dessa região é dirigida para exportação (FAO, 1997). Na América do Sul, por sua vez, a produção per capita de alimentos incrementou continuamente a partir do início da década de 90. De fato, considerando os dados de distribuição da produção mundial de alimentos e da população apresentados anteriormente, em contraposição à situação europeia, os países subdesenvolvidos têm a necessidade de aumentar a sua produção de alimentos. Para tanto, necessitariam aumentar a fronteira agrícola e/ou

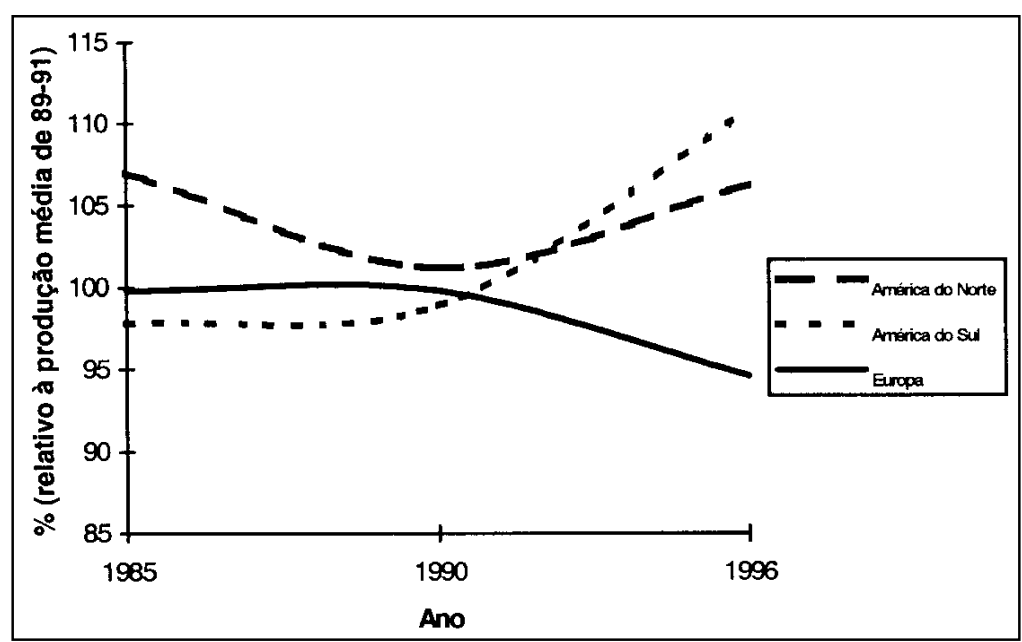

Figura 1 - Evolução da produção per capita de alimentos em algumas regiões do mundo (FAO, 1997).

Ciência Rural, v. 30, n. 4, 2000. 
aumentar a produtividade dos agroecossistemas já existentes nessas regiões. A primeira possibilidade implicaria a destruição de áreas consideradas hoje de preservação do ambiente e da biodiversidade natural, o que não seria apropriado. $\mathrm{O}$ aumento da produtividade, por sua vez, implicaria um input inevitável, embora variável, de energia nos agroecossistemas. A quantidade adicional de energia necessária poderia variar dependendo, num primeiro nível, da estrutura dos agroecossistemas e das práticas de manejo adotadas; num segundo nível, da estrutura de abastecimento adotada (se regionalizada ou não, implicando diferentes consumos de energia para transporte, armazenamento, processamento e comercialização dos alimentos) e, finalmente, num terceiro nível (do qual de certa maneira os demais dependem), das necessidades das populações por alimentos. Este último aspecto é particularmente importante, considerando que, já no início da década de setenta, era esperado que a crise energética viria a ter um profundo impacto na Revolução Verde, e que o uso do padrão agrícola intensivo para alimentar a população mundial da época (4 bilhões de habitantes), no nível norte-americano de consumo, significaria que $80 \%$ do gasto total de energia mundial seria utilizado somente pelo sistema alimentar (STEINHART \& STEINHART, 1974). Nessas condições, as reservas conhecidas de petróleo seriam esgotadas em 29 anos (PIMENTEL et al., 1973). Atualmente, se isso ocorresse, o incremento estimado do uso de energia cultural na biosfera seria de cinco vezes a atual (VAVRA, 1996), o que seria impossível e/ou inadmissível, face ao impacto ambiental que isso causaria e face à inexistência, até o momento, de uma alternativa técnica aceitável.

Das várias alternativas técnicas de fontes de energia que têm sido avaliadas na tentativa de substituir quantitativamente, embora não qualitativamente, o uso dos combustíveis fósseis, nenhuma foi considerada viável até o momento. Como exemplo, é estimado que se somente $2 \%$ dos desertos da Terra fossem cobertos com células fotovoltaicas seria produzido tanta energia quanto a gasta atualmente pela queima dos combustíveis fósseis. No entanto, isso não seria possível do ponto de vista prático (AMIGOS DE LA TIERRAPAÍSES BAJOS, 1994). A energia nuclear, por sua vez, seria uma fonte quantitativamente importante de energia. No entanto, a proliferação de sua manipulação seria extremamente perigosa, tanto devido aos altos riscos de ordem ambiental como devido às relações de poder que poderiam ser estabelecidas. A energia hidráulica e a energia da biomassa também não seriam viáveis, à medida que ocupariam grandes extensões de terra, as quais seriam necessárias para a produção de alimentos.

Portanto, o aumento no padrão de consumo de todas as populações pobres do mundo implicaria, necessariamente, a redução do consumo pelas populações ricas, cenário este pouco provável, considerando a estrutura de poder estabelecido no mundo atual. No entanto, os países subdesenvolvidos, individualmente, têm diferentes possibilidades de desenvolver programas de segurança alimentar, em função de diferenças nas condições sócio-econômicas, culturais, políticas e ambientais existentes entre eles. Nesse sentido, por exemplo, o Brasil teria um potencial produtivo bem maior que o de vastas regiões da África e da Ásia.

Não foi encontrado na literatura nenhum estudo de balanço energético dos cultivos ou sistemas de criação animal do Brasil. No entanto, com base nos resultados de balanço energético de sistemas de produção obtidos em outros países, apresentados anteriormente, é possível concluir que, face à grande dependência por insumos externos, energeticamente onerosos e esgotáveis e ainda, face à dependência e inseguridade alimentar do país, os agroecossistemas brasileiros são frágeis e insustentáveis, necessitando reavaliação num curto prazo, tanto em relação às políticas públicas para o setor quanto para o direcionamento da pesquisa. No entanto, para serem racionais, as novas proposições deverão Ter por base um modelo de produção agropecuário ambientalmente aceitável e, inevitavelmente, deverão constituir parte de um programa global, social e economicamente justo, de desenvolvimento do país.

\section{REFERÊNCIAS BIBLIOGRÁFICAS}

ALIER, J.M. Curso de economia ecológica. México DF Instituto Latinoamericano de Ecologia Social (Red de Fonnación Ambiental dei PNUMA), 1996. 62p. (material docente).

ALTIERI, M., MASERA, O. Desenvolvimento rural sustentável na América Latina: construindo de baixo para cima. m: ALMEIDA, J., NAVARRO, Z. (Coord.). Reconstruindo a agricultura: ideias $\mathrm{e}$ ideais na perspectiva do desenvolvimento rural sustentável. Porto Alegre : UFRGS, 1997. p.72-105.

ALTIERI, M.A., YURJEVIC, A. Agroecologia y desarrollo. Santiago : CLADES, 1991. La agroecologia y el desarrollo rural sostenible en América Latina: p.25-36.

AMIGOS DE LA TÏERRA-PAÍSES BAJOS. Los Países Bajos sustenibles. Amsterdan : Amigos de La Tierra-Países Bajos, 1994. 40p.

BRUM, A.J. Modernização da agricultura: trigo e soja. Petrópolis : Vozes, 1988. 200p.

BOWMAN, J.C. Animais úteis ao homem (Trad. VEIGA, M.F.S.). São Paulo : Universidade de São Paulo, 1980. V.20,74p. Coleção Temas de Biologia.

CHURCH, D.C. Digestivo physiology and nutritiou of ruminants. 2 ed.. Oregon : O \& Books, 1980. V.3,416p. 
COOK, E. The flow of energy in an industrial society. Scienüfic American, New York, v.225, p.135-144,1971.

DENARDI, R.A. Anotações sobre o perfil da agroindústria no Brasü. Curitiba : DESER, 1990. 42p.

FAO. Energia para Ia agricultura mundial. Roma : FAO, 1980a. Parte 1: Recursos energéticos mundiales: p. 1-42. Colección FAO: Agricultura, 7.

FAO. Energia para Ia agricultura mundial. Roma : FAO, 1980a. Parte 2: Los flujos energéticos en Ia agricultura: p. 4394. Colección FAO: Agricultura, 7.

FAO. Ensenanzas de Ia revolucion verde: hacia una nueva revolucion verde. Roma : FAO, 1995a. 19p. Texto provisional.

FAO. Production Yearbook. Roma : FAO, 1995b. v .49, 237p.

FAO. QuartelybuUetinofstatistics. Roma : FAO, 1997. v.10, n. $1 / 2,109$ p.

FARIA, V.P., CORSI, M. Índices de produtividade em gado leiteiro. In: FARIA, V.P. (Coord.). Produção de leite: conceitos básicos. Piracicaba : FEALQ, 1988. p.23-44.

GONÇALVES, J.O.N., GONZAGA, S.S., GIRARDI-DEIRO, A. M. Efeito do diferimento estacionai sobre a produção e composição botânica do campo natural, m. ENCONTRO DE PESQUISA E EXTENSÃO RURAL EM FORRAGEIRAS E NUTRIÇÃO ANIMAL, 1990, Injuí, RS. Anais... Ijuí: UFRGS/IPZFO/EMATER/COTRUUÍ, 1990. 232p. p.98.

HEITSCHMIDT, R.K., SHORT, R.E., GRINGS, E.E. Ecosystems, sustainability, and animal agriculture. Journal of Animal Science, Champaign, v.74, p.1395-1405,1996.

HECHT, S.B. La evolucion dei pensamiento agroecologico. Agroecologia y desarrollo. Santiago : CLADES, 1991. p.215 .

IBGE. Anuário Estatístico do Brasil. 1996. v.56, 1-1-8-32p.

JACQUES, A.V.A. Situação da pesquisa na área de plantas forrageiras e nutrição animal, to. ENCONTRO DE PESQUISA E EXTENSÃO RURAL EM FORRAGEIRAS E NUTRIÇÃO ANIMAL, 1990, Ijuí, RS. Anais... Ijuí: UFRGS/IPZFO/EMATER/COTRUUI', 1990. 232p. p. 12-19.
MARASCHIN, G.E. Oportunidades para uma eficiente produção animal baseada em pastagens. Ijuí : COTRUUÍ UFRGS,1981. 17p. Publicação exclusiva.

OLIVEIRA, A. Energia \& Sociedade. Ciência Hoje, v.5, p.3038,1987 .

OLTJEN, J.W., BECKETT, J.L. Role of runúnant livestock in sustainable agricultural systems. Journal of Animal Science, Champaign, v.74, p.1406-1409, 1996.

PIMENTEL, D., HURD, L.E., BELlOTTI, A.C., et al. Food production and me energy crisis. Science, Stanford, v. 182, p.443-449,1973.

REDE TECNOLOGIAS ALTERNATIVAS/SUL, totereonectando ideias e ideais na construção da agricultura do futuro. m: ALMEIDA, J., NAVARRO, Z. (Coord.). Reconstruindo a agricultura: ideias $e$ ideais na perspectiva do desenvolvimento rural sustentável. Porto Alegre : UFRGS, 1997. p.169-185.

SPEDDING, C.R.W. Sustainability in animal production systems. Animal Science, Cambridge, v.61, p.1-8,1995.

STEINHART, J.S., STEINHART, C.E. Energy use in me U.S. food systems. Science, Stanford, v.184, p.307-316,1974.

TAMMINGA, S. A review on environmental impacts of nutritional strategies in ruminants. Journal of Animal Science, Champaign, v.74, p.3112-3124,1996.

VAN SOEST, P. Nutritional ecology of the runúnant. New York : Comell University, 1982.373p.

VAVRA, M. Sustainability of animal production systems: na ecological perspective. Journal of Animal Science, Champaign, v.74, p.1418-1423, 1996.

VAVRA, M. Ecological perspective of grazing management. In. GOMIDE, J. A (Ed.). Simpósio internacional sobre produção animal em pastejo. Viçosa : UFV, 1997. p.333348.

WATHES, C.M. Energetic efficiencies of altemative systems of egg production. Poultry Science, Champaign, v.60, p.523527,1981 .

ZIMMER, A.H., EUCLIDES FILHO, K. As pastagens e a pecuária de corte brasileira, to. GOMIDE, J.A (Ed.). Simpósio internacional sobre produção animal em pastejo. Viçosa: UFV, 1997. p.349-380.

Ciência Rural, v. 30, n. 4, 2000. 